\title{
Study on Green Highway Construction in Mountainous Hilly Area
}

\author{
Ke $\mathrm{Yao}^{1 *}$, Mengyue $\mathrm{Li}^{1}$, Qingqing Fan ${ }^{1}$, Xiangchen Meng ${ }^{2}$, Guojun $\mathrm{Hao}^{1}$ \\ ${ }^{1}$ Guangdong Provincial Transport Planning and Research Center, Guangzhou, 510101, China \\ ${ }^{2}$ College of Civil Engineering, Beijing Jiaotong University, Beijing, 100044, China
}

\begin{abstract}
The article takes the Shaoxin Expressway as an example. Based on the construction characteristics of the project, it analyzes the construction requirements for the green highway of the project. From the safe and ecological construction of the tunnel, the ecological safety guarantee in the environmentally sensitive areas, the expansion of the highway tourism functions, the wisdom monitoring of highway construction operations and other aspects, this article systematically analyzes the contents of green highway construction in mountainous hilly areas, and it can provide a technical reference for similar green roads construction projects.
\end{abstract}

\section{Introduction}

Modern transportation development must adhere to the concept of green and sustainable development, and realize the harmonious integration of transportation development, resources and environment. Green highway is the embodiment of ecological civilization and green transportation development concepts in the field of highway construction. To build a green highway, we must focus on resource conservation, environmental friendliness, energy efficiency, and service improvement during the full life cycle of the highway design, construction, operation and maintenance to achieve sustainable development of highway construction, the development of highway facilities and harmonious symbiosis of humanity and natural environment. How to develop green highways construction in mountainous hilly areas will be analyzed in this article.

\section{Research object}

The article takes Shaoxin Expressway as an example to carry out research on green highway construction in mountainous hilly areas. The Shaoxing Expressway is located in Shaoguan City and Huizhou City, the northern mountainous area of Guangdong Province. The total length of the route is about $85.291 \mathrm{~km}$, of which the bridge length is $16.032 \mathrm{~km}$, the tunnel length is $21.718 \mathrm{~m}$, and the bridge-tunnel ratio is $46.8 \%$. The project provides convenient access for vehicles traveling south to areas such as Huizhou City and Shenzhen City.

\section{Technical demand analysis}

\subsection{Analysis of project characteristics:}

- The Shaoxin Expressway runs through the mountainous area of northern Guangdong Province. Terrain along the route is complex and vegetation coverage is high. Nature reserves, scenic spots, forest parks and drinking water sources protection areas are densely covered. Ecological environment is extremely sensitive.

- Shaoguan City, where Shaoxin Expressway is located, is one of the regions with the richest tourism resources in Guangdong Province. It has 17 world-class and nationallevel scenic spots and more than 100 provincial-level and lower-level scenic spots. Travel services are in great demand.

- The Shaoxin Expressway Bridge and Tunnel project is large in scale, with 48 bridges and 9 tunnels, of which The Songshan Tunnel is $7964 \mathrm{~m}$ in length, and is the longest highway tunnel in Guangdong Province. It is difficult to control safety and environmental protection during the construction and operation of the project.

\subsection{Construction demand analysis}

Based on the construction characteristics of the Shaoxin Expressway project, "Green, Tourism, and Wisdom" were identified as the construction goals of the highway, and the following construction demand of the project were analyzed:

- Safe, smart, low-carbon and environmentallyfriendly tunnel construction.

As there are many long tunnels in the project, safety and environmental protection issues during the tunnel construction period are prominent, the pressure on traffic safety guarantee and tunnel energy conservation during tunnel operation are very high. It is necessary to vigorously promote the safe and intelligent, low-carbon and environmentally-friendly tunnel construction technologies such as tunnel construction safety

\footnotetext{
*Corresponding author's e-mail: 45843338@qq.com
} 
monitoring, low-carbon environmental construction, tunnel operation safety management and energy saving, etc.

- Environmental safety guarantee for water source protection areas.

As there are many environmentally sensitive points along the project, local road sections pass through the drinking water source protection area. Construction has a large impact on the water quality of the water source protection area and water environment risks are prominent during the project operation period. It is necessary to integrate and apply environmental safety protection technologies such as road surface runoff pollution control, safety protection, monitoring and early warning for environmental risk accident to reduce the impact of highway construction on drinking water source protection areas.

- Expansion of road tourism functions.

With abundant tourism resources along the project, construction of tourist roads has become its construction goal. The integrated design and construction of highway landscapes, and creating tourist destination service areas are needed, and the technology of road tourism function expansion needs to be promoted and applied.

- Construction of smart highway platform.

Project construction quality, safety, and environmental protection are difficult to control. So the innovative models and technologies of environmental protection and safety, quality control are needed to implement all-round intelligent management and control during the construction process. Meanwhile, the smart travel service technology needs to be applied during operation.

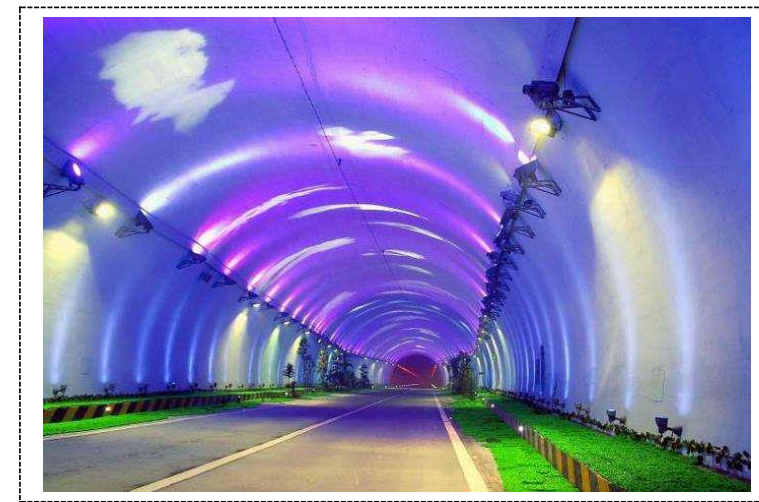

Figure 1. Application of landscape lighting belt in tunnel

- Technology of multifunctional energy storage luminescent material for tunnels.

The multifunctional energy-storage luminescent material has the functions of increasing brightness and delaying light emission. Under the action of a light source, electron transitions outside the nucleus will be generated to form the visible spectrum. When leaving the light source, the electrons outside the nucleus return to form a long time-lapse luminescence again. The combination of these materials and tunnel control system of LED intelligent lighting can greatly save lighting

\section{Main research contents}

\subsection{Highway green ecological construction}

\subsubsection{Building safe, smart, low-carbon and environmentally friendly tunnels}

- Security management system based on panoramic video for long tunnel operation.

This system is constructed by real-time video stitching technology and directional sound push technology which stitches the content of multiple video windows in real time into a complete panoramic video and realizes function, such as the panoramic display of the tunnel video, object tracking, intelligent recognition of abnormal behaviour, and automatic inspection. The system can also directly push specific sound information to specific objects, prompt warning information, and avoid affecting the acoustic environment in the tunnel.

- Control technology of noise and landscape illumination environment in extra-long tunnel.

The noise of Songshan extra-long tunnel in this project mainly comes from the operation of ventilation fans and vehicle driving. The sound-absorbing materials and structures with different acoustic characteristics are used to reduce the level of noise on inner wall and top of tunnel. Meanwhile, using landscape lighting belt at appropriate sections of the tunnel will change the driving environment, solving the problem of monotonous driving environment in the long tunnel, and also reducing driver's visual fatigue.

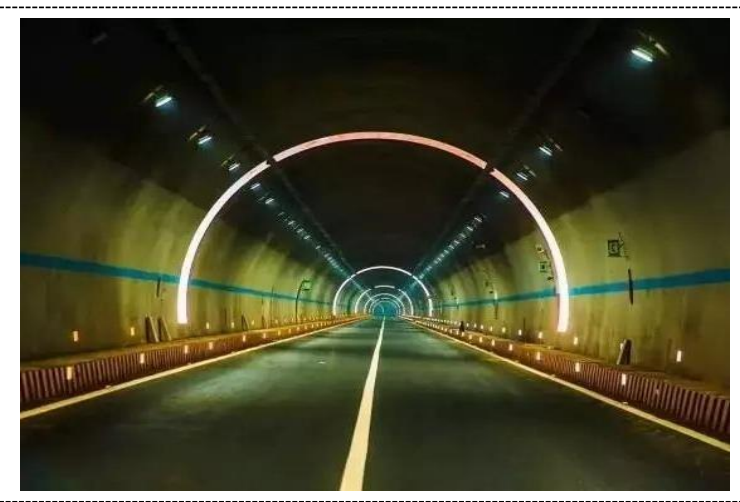

Figure 2. Application of tunnel energy storage luminous reflector

energy consumption and improve visible distance and safety guarantee.

- Enhancement technology of outside dimming and entrance lighting.

Cutting face tunnel portal and other forms make full use of natural light. Facilities outside the cave should be equipped with green belts dimming, transparent sheds, shading awnings, etc., or the tunnel entrance and exit should be paved with light-coloured non-slip materials with high brightness. It can improve the retroreflective coefficient of the pavement brightness at the entrance and exit of the tunnel, effectively reduce the lighting 
standards at the entrance and transition sections, and achieve the purpose of safety and energy saving.

- Comprehensive utilization technology of tunnel slag.

Investigate the characteristics of tunnel slag to scientifically determine the comprehensive utilization direction of cave slag. The cave slag is processed into road aggregate, concrete aggregate, embankment filling, etc. by using mobile and miniaturized cave slag processing equipment and applying aggregate and mechanism sand processing technology to achieve the maximum comprehensive utilization of tunnel slag.

- Combining temporary with permanent technology of tunnel construction electricity and fire protection water.

According to the layout of the permanent power facilities for highway operations, the construction of permanent power lines and facilities will be completed before the tunnel. The permanent power facilities are used to provide centralized power which supply for the tunnel construction to ensure the power supply capacity and power quality during the construction period. At the same time, it can save the comprehensive cost in "Construction Management Maintenance". Similarly, before the construction of the tunnel, a fire-fighting pool will be constructed. It will be used as a treatment facility for tunnel gushing water and construction wastewater during the construction to realize the combining temporary with permanent of the tunnel fire-fighting pool.

\subsubsection{Ensuring the environmental safety of water source protection areas}

- Surface run-off pollution control system of road area. This system mainly includes ecological side ditch and pavement runoff collection and processing.

The ecological side ditch system consists of engineering units such as vegetation, earth ditch, water collecting well, and side ditch which is buried by a cover. Vegetation can play a role of intercepting oil in road runoff, adsorbing heavy metals, sedimentation and suspending solids. Shallow dish-shaped dark side furrows are generally used for planting grass.

Road runoff is collected by ecological side ditch and shoulder drainage ditch. Bridge runoff is collected by inlet and drainage pipe. Road and bridge runoff treatment system is divided into non-accident rainwater treatment unit and hazardous chemical accident water emergency storage unit. The electric control valve is used for switching control between the two units. The nonaccident rainwater treatment unit uses the combination of an oil trap sedimentation tank and an artificial wetland or a biological filter bed system for in-depth treatment. The emergency storage unit for hazardous chemical accident water takes the form of a pool.

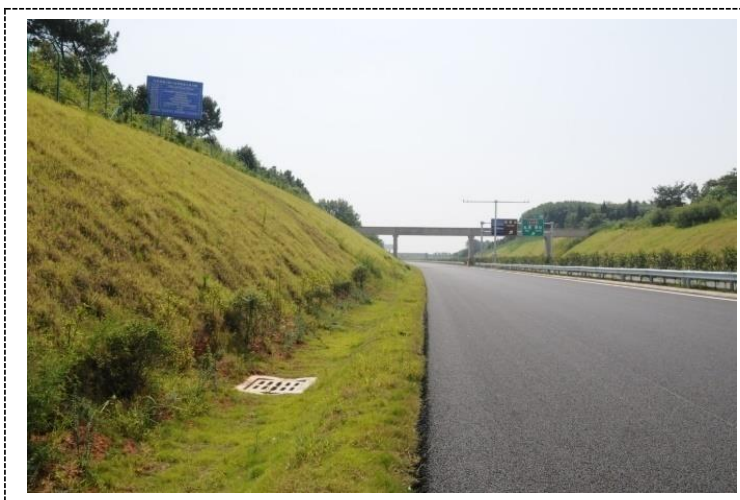

Figure 3. Ecological roadside ditch system

- Safety guarantee system for environmental risks and accidents. The security system mainly uses roadside vibration band technology and new safety protection technology.

The roadside vibration band is a vibration belt formed by interval milling on hard shoulders. It uses the vibration and noise generated by the vehicle driving on the road to achieve the effect of warning the driver and contribute to prevent roadside traffic accidents caused by driving fatigue, negligence or bad weather.

The new safety protection technology mainly uses new types of protection facilities such as oriented anticollision pads and rotating guardrails reasonably. Utilizing the principle of buffering energy absorption of steel members, adopting special-shaped steel plates as the main energy-absorbing members, the oriented anticollision pad is mainly used for the safety protection of

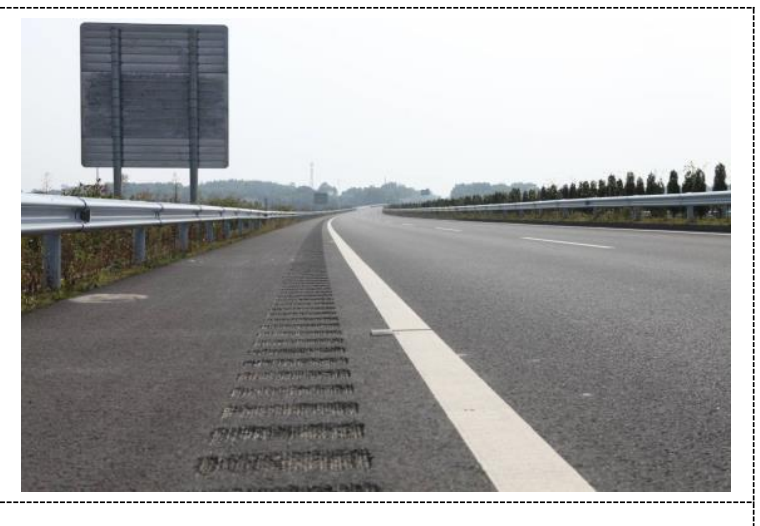

Figure 4. Roadside vibration band application

interchange triangle areas, tunnel openings and toll islands. Besides, the rotating guardrail is mainly used for roadside guardrails with small radius curves by rolling friction generated between the rotating bucket of the guardrail and the out-of-control vehicle to induce the vehicle to move forward, quickly drive out of the collision area for reducing vehicle collision damage.

- Technology of environmental risk accident monitoring and early warning. The technology mainly includes identification and warning of hazardous chemical transportation vehicles, monitoring and early warning of water environment risk.

By integrating the data of satellite positioning, vehicle transportation, and vehicle inspection device monitoring about hazardous chemical vehicles, its identification system is constructed to realize dynamic monitoring of the hazardous chemical vehicles operating 
state. On the basis of the identification system, it continues to develop a warning system for hazardous chemicals transportation vehicles, and push warning information such as safe driving to those entering the sections of water environment sensitive areas.

Water environment risk monitoring and early warning are mainly completed by three parts: video surveillance of dangerous chemical transportation vehicles, front-end runoff monitoring and command of emergency response. The three parts constitute a complete system to monitor the operation status of dangerous chemical transportation vehicles on sensitive water sections, and organize the handling of environmental accidents.

\subsubsection{Highway Landscape Fusion Design and Construction}

- Technology of surveying highway landscape resources based on 3DGIS and UAV remote sensing platform.

It mainly uses the UAV remote sensing platform to obtain high-resolution images of highway roads, and three-dimensional display of 3DGIS, viewshed analysis and other functions to establish a three-dimensional visualization system of highway landscape resources, and implements survey analysis and evaluation of road landscape resources.

\subsection{Improvement of road tourism functions}

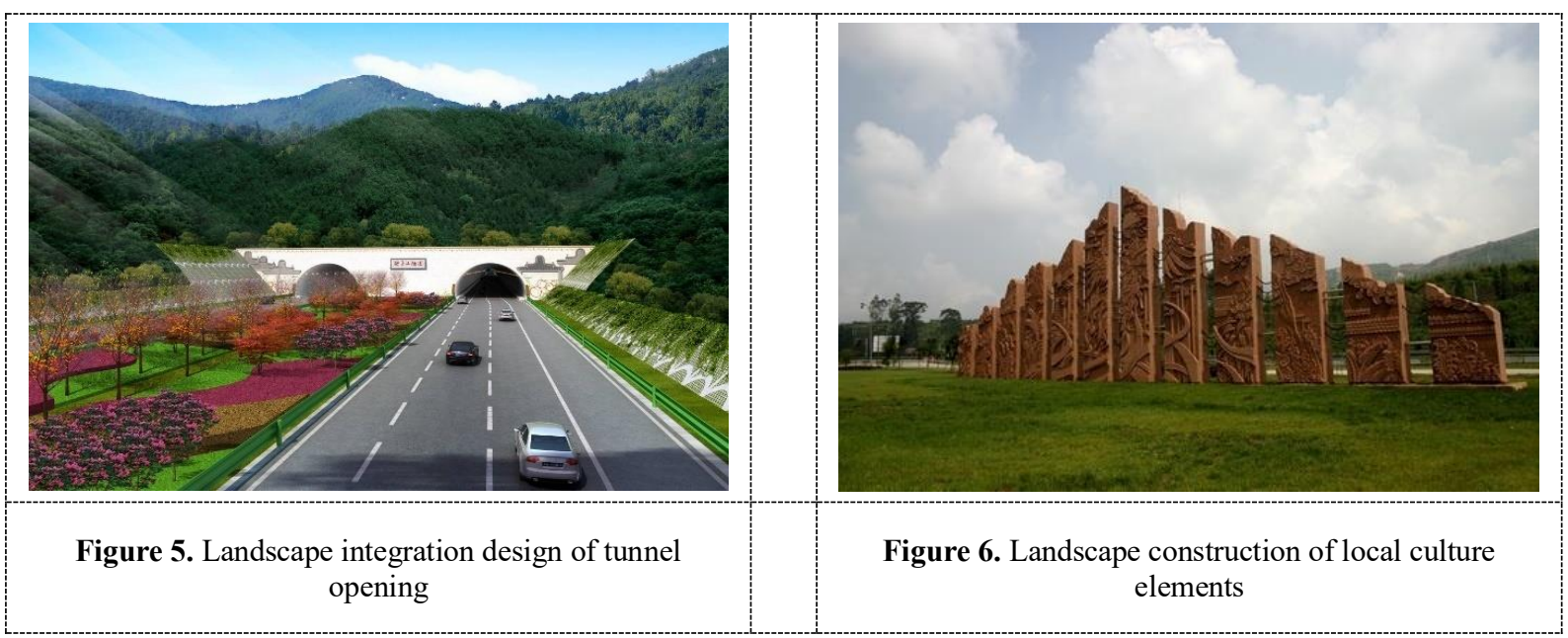

- Technology of highway landscape design based on integration.

It is mainly based on the theory of landscape integration to construct a framework of highway landscape integration index, carry out the coordinated design of highway alignment and structures, and the integrated design of highways with natural and cultural environments, focusing on the node landscape space design and terrain design of interchange and service areas, vegetation landscape level design and colour design.

- Techniques for highway native landscape construction.

Based on the local environment where the highway is located, it can use local materials, learn from local cultural elements, and apply local technical measures to achieve the localization of highway landscapes and create distinctive highway landscapes. Meanwhile, it can

reduce project costs, display regional culture, and expand the tourism function of highways.

\subsubsection{Creating tourist destination service areas}

- Construction technology of service area with characteristic theme.

Relying on the regional culture and characteristic resources, on the basis of satisfying the traditional service functions, shape the unique theme, expand the tourism service function, and turn the service area into a multifunctional characteristic theme one with places of break in transportation, integrated services, leisure shopping, accommodation and catering, cultural experience, entertainment and landscape space. 


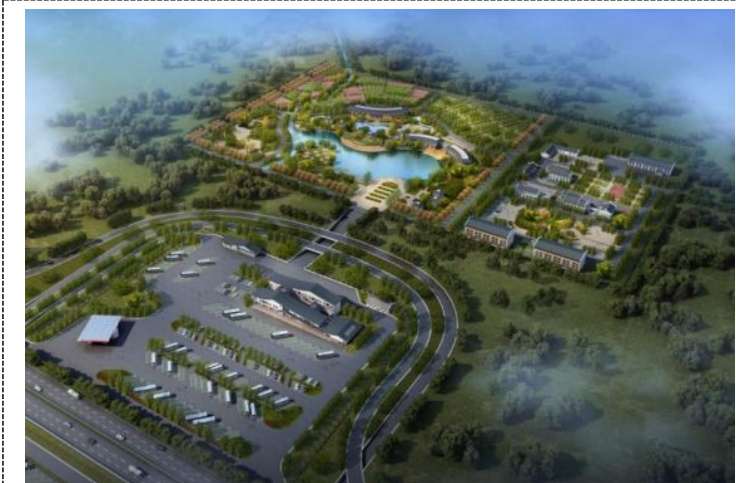

Figure 7. Scheme of Meikeng Service Area of Shaoxin Expressway

- Technology of green energy development and green building application.

Reasonably develop and use green energy application systems such as solar photovoltaic power generation facilities, photovoltaic buildings, wind-solar hybrid power generation facilities, solar hot water systems, ground (water) source heat pump systems, and air source heat pump systems in service areas, and build electric vehicle charging piles and LNG processing stations to meet the public's various travel service needs. The green buildings in the service area mainly carry out energysaving design for the building's doors, windows, walls, roof, atrium and envelope structure, and also carry out natural ventilation and natural light utilization design to maximize the energy-saving effect.

- Technology of rainwater and sewage utilization.

The technology of rainwater utilization is to construct a rainwater utilization system consisting of traffic lanes with permeable pavement, permeable ecological parking lot, sunken green space, and green field rainwater sprinkler irrigation system, so as to realize the recycling of rainwater in service areas. The sewage recycling system in service areas collects and recycles the toilet black water, yellow water and grey water, respectively. Black water and yellow water are used as a greening and agricultural organic fertilizer after septic tank aeration treatment, and grey water is used for flushing toilets and surrounding greening after treatment to realize the reuse of water in service areas.

\subsection{Construction of highway smart platform}

\subsubsection{Highway smart construction}

- $\quad$ Smart site management platform.

According to the needs of project management, the platform can be subdivided into smart site cloud platforms, smart site laboratories, smart mixing stations, intelligent compaction systems for subgrades and pavements, smart management and control systems for tunnel construction safety, smart environment and energy consumption monitoring systems. Utilizing the Internet and technology of cloud computing, through video monitoring, process monitoring, data interworking,

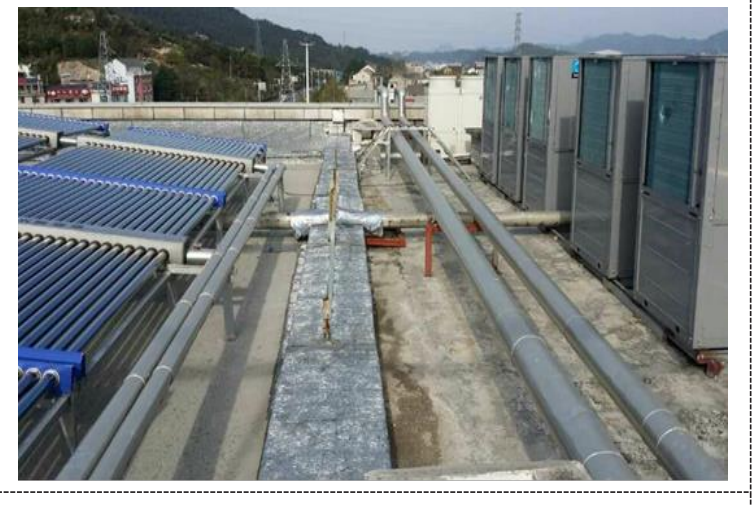

Figure 8. Air source heat pump + solar water heating system

security early warning, mobile terminals and other smart facilities to collect real-time construction conditions, it can display on the management platform in a visual form to realize real-time intelligent supervision of highway construction.

- Environmental protection management and control platform with integration of heaven and earth.

Focusing on the environmental protection management requirements of highway construction, using drone remote sensing technology as a platform, combined with multi-source remote sensing data to develop a technical method based on the integration of heaven and earth of extracting environmental data during the highway construction period, for the supervision, monitoring and acceptance of environmental protection and water conservation.

\subsubsection{Highway smart operation}

- Big data visualization system for highway traffic. According to the needs of project management, some systems such as the road network operation data monitoring and mining analysis, the integration of electromechanical systems, the safety monitoring and early warning of high and steep slope operations, the monitoring of super-long tunnels, and disaster prevention and rescue will be systematically integrated to construct a big data visualization system for highway traffic. Through systematic analysis and processing, visualization and real-time monitoring of project operation, it can provide project management units for data support.

- Highway inspection system by using UAV.

Utilizing UAV platform with professional equipment to realize remote control, telemetry, tracking, positioning and digital transmission of UAV through GPS, radar, radio data transmission and other control equipment, it is used for road property patrol and maintenance, highway disease monitoring, driving safety management, emergency early warning processing, etc. to achieve comprehensive intelligent management and control of highways. 


\section{Conclusions}

Green highway construction is based on the overall goals of resource conservation, environmental friendliness, energy efficiency, and service improvement. Highway projects in different regions have different regional characteristics, project requirements, and construction difficulties. Green is a concept of construction and a technical method to solve difficulties of project in particular. To realize the green construction of highway projects, it is necessary to carry out an in-depth analysis of the project characteristics and construction needs, determine the green construction goals of the project, and study and filter specific green technical measures. Since the mountainous hilly area has the characteristics of complex terrain, many environmentally sensitive points, rich tourism resources, high bridge-tunnel ratio, and difficult construction, etc, it will be the key content of green highway construction in mountainous hilly areas that organizing green construction around the safe and ecological construction of bridges and tunnels, the ecological safety guarantee of environmentally sensitive areas, the creation of landscapes along the highway, the enhancement of tourism functions and the intelligent management of highway construction operations. The green technical measures proposed in this paper will provide reference for similar projects to implement green construction.

\section{References}

1. Ouyang, B., Li, Z.K. (2014) Strategic thinking of green highway development. Traffic construction and management, (22): 128-132+136.

2. Yang, M.Y., Li, S.L., Wang, X.Y. (2019) Application of concept of green highway in tunnel engineering. Northern communications, (03): 79$82+85$.

3. Chen, T.X., Liang, J.C., Li, P. (2018) Construction of key technologies and applications based on concept of green highway. Journal of Highway and Transportation Research and Development (Edition of applied technology), 14(08): 9-10.

4. He, J. (2018) Preliminary innovation and practice of tourism highway design concept. Highway, 63(11): 220-230.

5. Zhang, W. (2019) Highway landscape design based on concept of green highway. Hunan communication science and technology, 45(03): $79-81+155$.

6. Zhang,Z.J., Zhang,L.J., Zhang,Y. (2010) Effect of expressways on environment pollution and the protection strategies. Journal of Southwest China Normal University (Natural Science Edition), 35(02):127-131.
7. Jian,M.F., Li,X.B., Zhao,H., Liao,Z.W. (2018) Research on "Green" control of green highway construction in Jiangxi province. Energy Conservation \& Environmental Protection in Transportation, 14(05):58-60+66.

8. Feng,K.W. (2019) Discussion on green road construction under the concept of sustainable development. Green Environmental Protection Building Materials, (09): 116+119.

9. Peng,L., Liu,H.F., Zhu,J., Xiao,W.H. (2019) Research on implementation plan of national and provincial highways in the mountainous areas based on green highway concept. Highway, (06):16-19.

10. Zhang,L., Zhang.L., Zhang,G.Q. (2019) Construction and management practice of green expressway in mountainous area of northern Guangdong. Road Machinery \& Construction Mechanization, (04):123-127. 